Int. J. Environ. Res. Public Health 2007, 4(1), 61-67

International Journal of

Environmental Research and Public Health

ISSN 1661-7827

www.jorjerphorg

(c) 2007 by MDPI

\title{
Inactivation of Adenovirus Type 5, Rotavirus WA and Male Specific Coliphage (MS2) in Biosolids by Lime Stabilization
}

\author{
Jacqueline J. Hansen ${ }^{1}$, Paul S. Warden ${ }^{2}$ and Aaron B. Margolin ${ }^{1 *}$ \\ ${ }^{1}$ Department of Microbiology, Virology and Waterborne Disease Laboratory, Rudman Hall, University of New Hampshire, \\ Durham, NH, 03824. \\ ${ }^{2}$ Analytical Services, Inc. 130 Allen Brook Lane, Williston, VT 05495 \\ *Correspondence to Dr. Aaron B. Margolin. Email: aaron.margoin@unh.edu
}

Received: 02 March 2007 / Accepted: 15 March 2007 / Published: 31 March 2007

\begin{abstract}
The use of lime to reduce or eliminate pathogen content is a cost-effective treatment currently employed in many Class B biosolids production plants in the United States. A bench scale model of lime stabilization was designed to evaluate the survival of adenovirus type 5, rotavirus Wa, and the male specific bacteriophage, MS2, in various matrices. Each virus was initially evaluated independently in a reverse osmosis treated water matrix limed with an aqueous solution of calcium hydroxide for $24-\mathrm{hr}$ at $22 \pm 5^{\circ} \mathrm{C}$. In all R/O water trials, adenovirus type 5, rotavirus Wa and MS2 were below detectable levels $\left(<10^{0.5} \mathrm{TCID}_{50} / \mathrm{mL}\right.$ and $<1 \mathrm{PFU} / \mathrm{mL}$ respectively) following 0.1 -hr of liming. Adenovirus type 5, rotavirus $\mathrm{Wa}$, and MS2, were inoculated into composted, raw and previously limed matrices, representative of sludge and biosolids, to achieve a final concentration of approximately $10^{4} \mathrm{PFU}$ or $\mathrm{TCID}_{50} / \mathrm{mL}$. Each matrix was limed for 24-hr at $22 \pm 5^{\circ} \mathrm{C}$ and $4 \pm 2^{\circ} \mathrm{C}$. In all trials virus was below detectable levels following a 24-hr incubation. The time required for viral inactivation varied depending on the temperature and sample matrix. This research demonstrates reduction of adenovirus type 5, rotavirus Wa, and male-specific bacteriophage, in water, sludge and biosolids matrices following addition of an $8 \%$ calcium hydroxide slurry to achieve a $\mathrm{pH}$ of 12 for 2-hr reduced to 11.5 for 22 -hr by addition of $0.1 \mathrm{~N} \mathrm{HCl}$. In these trials, MS2 was a conservative indicator of the efficacy of lime stabilization of adenovirus Type 5 and rotavirus Wa and therefore is proposed as a useful indicator organism.
\end{abstract}

Keywords: Biosolids, lime stabilization, adenovirus, rotavirus, bacteriophage

\section{Introduction}

The use of lime to reduce or eliminate pathogen content in sewage sludge represents a relatively cost effective method of treatment by which Class B sludge can be generated [1]. During lime stabilization calcium hydroxide $\left(\mathrm{Ca}(\mathrm{OH})_{2}\right)$ or calcium oxide $(\mathrm{CaO})$ is added to elevate the $\mathrm{pH}$ of the matrix for a defined period of time. To meet class $\mathrm{B}$ requirements for both the pathogen and vector attraction reduction the $\mathrm{pH}$ must be elevated to $=12$ for two hours and be maintained at $=11.5$ for a minimum of twenty-two hours. Lime has been historically used for the disinfection and odor suppression of solid wastes. Lime treatment reduces the number of microorganisms in discharged effluent when calcium hydroxide binds to the solid material, facilitating flocculation in sedimentation or flotation processes while the hydroxide alkalinity of the lime has an antimicrobial effect [2-5]. Installation of a lime stabilization treatment system is relatively rapid, with minimal capital costs, compared to alternative treatment technologies, and generates a relatively safe and sustainable product [1].

Qualitative research has demonstrated the bactericidal properties of lime through inactivation of Escherichia coli and Salmonella $[1,2,6]$. Previous research to evaluate the persistence of enteric virus under lime stabilization conditions has demonstrated that a high $\mathrm{pH}$ is effective at reducing or eliminating Poliovirus type 1 from sludge [2, 7-9], however, there is little information to indicate the removal and inactivation of other human pathogenic viruses, such as rotavirus and adenovirus, which were not cultivatable when original liming studies were conducted [10]. Rotaviruses have been detected in water, wastewater, and more recently in biosolids, although very little data exists on their occurrence in biosolids. These viruses are extremely resistant to environmental stress due to the presence of a double icosahedral shell [11-13]. Rotavirus Wa was chosen as a representative of the Reoviridae because it is of human origin and is quantifiable using the plaque assay methodology. 
Adenoviruses are one of the most common and persistent viruses detected in wastewater and have been transmitted by both recreational and drinking waters [1315]. Adenovirus type 5 manifests itself primarily as an upper respiratory tract infection. It was chosen as a representative of the Adenoviridae because of its similarity to Adenovirus 40 and 41, which are transmitted by the fecal-oral mode. Adenovirus type 5 can be more readily propagated and enumerated using available cell culture techniques in comparison to Adenovirus 40 and 41.

There has been little research conducted on the occurrence of enteric viruses in biosolids in recent years. The prevalence of enteroviruses in biosolids, specifically poliovirus, is known, yet for many treatments the amount of data on virus removal is limited. With new cell culture detection techniques it is now possible to evaluate the persistence of pathogens such as rotavirus and adenovirus that were previously not cultivatable. In addition, there is very little data available comparing the inactivation of bacteriophages, specifically MS2, and enteric viruses during traditionally employed sludge treatment processes. The similar morphology, structure and behavior of Fspecific RNA bacteriophages, as well as other phages, to that of human enteric viruses, suggests that they may, as a group, be used as a surrogate for treatment process controls and may also act as an indicator organism for other enteric viruses. Currently no data is available comparing the inactivation of bacteriophage to that of rotavirus or adenovirus during traditionally employed sludge treatment processes. Recovery of virus from sludge and biosolids matrices is difficult due to the association of virions and sludge/biosolids components. The identification of a representative indicator that is prevalent, easy and inexpensive to detect would provide an alternative to the labor intensive and often inconclusive cell culture techniques that are currently used for detection of virus in sludge and biosolids matrices.

The goal of the following investigation was to evaluate the inactivation of the representative viral pathogens Rotavirus $\mathrm{Wa}$ and Adenovirus Type 5 under conditions simulating Class B lime stabilization and compare this inactivation to that observed for the malespecific bacteriophage MS2.

\section{Materials and Methods}

\section{Bacteriophage Preparation}

Bacteriophage MS2, which belongs to the family leviviridae, was used as the reference bacteriophage for Fspecific RNA bacteriophages. Bacteriophage was propagated and enumerated using an $E$. coli host harboring a conjugative plasmid conferring both streptomycin and ampicillin resistance and pilus production (E. coli F. Amp HFR). MS2 was enumerated by plaque assay with $E$. coli F. Amp using a double agar overlay technique [16]. Plaques were observed and enumerated following 18 to 24$\mathrm{hr}$ of incubation at $37^{\circ} \mathrm{C} \pm 2{ }^{\circ} \mathrm{C}$. Bacteriophage was inoculated along with adenovirus and rotavirus in each lime stabilization trial performed to act as an internal biological control and to compare the inactivation of each in an effort to determine whether bacteriophage could be used as a surrogate and indicator of viral inactivation during monitoring.

\section{Adenovirus Type 5}

Adenovirus Type 5 (ATCC VR-1523) was propagated within A549 cells grown to $90 \%$ confluency in closed 75 $\mathrm{cm}^{2}$ cell culture flasks at $37 \pm 2{ }^{\circ} \mathrm{C}$ with Eagle's Minimum Essential Medium (MEM) (Sigma) and L-15 Medium supplemented with 10\% Fetal Bovine Serum (FBS) [17]. Confluent monolayers of A549 cells were inoculated with adenovirus type 5 and incubated at $37 \pm 2^{\circ} \mathrm{C}$ for 60 minutes to permit viral attachment. Following incubation, a maintenance medium consisting of Eagle's MEM supplemented with $2 \%$ FBS was added and cells were incubated at $37 \pm 2{ }^{\circ} \mathrm{C}$ and observed daily for cytopathic effect. Once a generalized cytopathic effect was achieved, flasks were freeze-thawed to liberate viruses trapped within cells. The resultant suspension was centrifuged at $1000 \mathrm{x} \mathrm{g}$ for 10 minutes to separate cellular debris from virus present in the supernatant. Adenovirus was enumerated using the TCID $_{50}$ (Tissue Culture Infectious Dose) method established by Reed and Muench ${ }^{18}$. Confluent monolayers of A549 cells were inoculated according to $\mathrm{TCID}_{50}$ protocols with $0.025 \mathrm{~mL}$ of the appropriate viral dilution. Virus adsorbed to cells for $1.5-\mathrm{hr}$ at $37 \pm 2{ }^{\circ} \mathrm{C}$. Following adsorption, a maintenance medium consisting of MEM supplemented with $2 \%$ FBS was added. Plates were incubated at $37 \pm 2{ }^{\circ} \mathrm{C}$ in $5 \% \mathrm{CO}_{2}$ with humidity and observed for cytopathic effect for 14 days post-inoculation. The number of positive wells was determined for each dilution and used to calculate a TCID $_{50}$ titer. Enumerated stocks of adenovirus type 5 were stored in cryovials at $-80 \pm 2{ }^{\circ} \mathrm{C}$.

\section{Rotavirus $W a$}

Rotavirus Wa strain (ATCC VR-2018) was propagated within Ma104 cells [17]. Cells were grown to $90 \%$ confluency in closed seventy-five $\mathrm{cm}^{2}$ cell culture flasks at $37 \pm 2{ }^{\circ} \mathrm{C}$ using Eagle's MEM supplemented with $10 \%$ FBS. Prior to infection, medium was removed from each flask and the cells were washed twice with serum-free MEM. Virus adsorbed to cells for 60 minutes at $37 \pm 2^{\circ} \mathrm{C}$ at which time $15 \mathrm{~mL}$ of Eagle's MEM supplemented with $5 \mu \mathrm{g} / \mathrm{mL}$ of trypsin (Gibco) was added to each flask and flasks were incubated at $37 \pm 2{ }^{\circ} \mathrm{C}$. Flasks were observed daily for cytopathic effect. Once a generalized cytopathic effect was achieved, virus was liberated from the cells by rapid freeze-thaw. The resultant viral suspension was transferred to a $15 \mathrm{~mL}$ conical tube and centrifuged at 1000 $\mathrm{x} g$ for 10 minutes to separate cellular debris from virus present in the supernatant. Virus was enumerated using a modified plaque-forming unit (PFU) method [17]. Ma104 cells were grown to confluency with $5 \% \mathrm{CO}_{2}$ in 12 -well cell culture plates with Eagle's MEM supplemented with 
$10 \%$ FBS. Cells were thoroughly washed prior to infection with serum-free MEM. Cells were inoculated in triplicate with $0.1 \mathrm{~mL}$ of the appropriate viral dilution. Plates were incubated in $5 \% \quad \mathrm{CO}_{2}$ for 60 minutes with continual rocking to permit viral adsorption and maintain hydration of cells. Following adsorption, $2 \mathrm{~mL}$ of an agar overlay maintenance medium consisting of $2 \mathrm{X}$ MEM supplemented with $1 \mu \mathrm{g} / \mathrm{mL}$ trypsin (Gibco), and 2\% agar (Sigma) was added. Following addition of overlay, the agar was permitted to solidify and the plates were returned to the $5 \% \mathrm{CO}_{2}$ incubator. Plates were incubated for 4 days at which time $2 \mathrm{~mL}$ of $10 \%$ formaldehyde in normal saline solution was added to each well. Plates were returned to the $\mathrm{CO}_{2}$ incubator for overnight incubation. Solid overlay was removed from wells by rinsing under warm tap water and $2 \mathrm{~mL}$ of a $0.1 \%$ crystal violet solution was added to each well to permit visualization of plaques. Plaques were quantified and results from duplicate flasks averaged to calculate a titer.

\section{Elution of Viruses from Sludge Samples}

Samples were evaluated for total culturable viruses in accordance with procedures outlined in the EPA part 503 rules for recovery and assay of viruses from sludge [19]. The underlying principle in this methodology is based upon the charge interaction that takes place between the positively charged solids material and the negatively charged virions potentially contained within the sample matrix. Viruses adsorbed to the sludge solids were eluted, initially concentrated by centrifugation and then further concentrated by organic flocculation. Bacterial and/or fungal decontamination prior to testing in cell culture was achieved by incubation with an antibiotic/antimycotic.

Liquid wastewater samples $(<0.1 \%$ total solids $)$ were conditioned prior to elution by homogenizing in a Waring ${ }^{\circledR}$ blender on the high setting for five minutes, at which time $1.0 \mathrm{~mL}$ of aluminum chloride was added and the $\mathrm{pH}$ of the solution adjusted to 3.5 with $1 \mathrm{~N} \mathrm{HCl}$. The sample was mixed at $150 \mathrm{rpm}$ for 30 minutes and subsequently centrifuged at $2500 \mathrm{x}$ g for 15 minutes at $4 \pm 2^{\circ} \mathrm{C}$. The supernate was discarded and the pellet resuspended.

Solid samples were blended for 5 minutes with 100 $\mathrm{mL}$ of $\mathrm{R} / \mathrm{O}$ treated water in a Waring ${ }^{\circledR}$ blender. The sample was mixed with an equal volume of $20 \%$ beef extract solution for 30 minutes in a shaker set at $150 \mathrm{rpm}$ and subsequently centrifuged at $10,000 \mathrm{x}$ g for 30 minutes at 4 $\pm 2^{\circ} \mathrm{C}$. The supernatant fluid was decanted and the appropriate volume of distilled water was added to the supernatant to bring the final concentration of beef extract to $3 \%$. The resultant eluate was transferred to a clean centrifuge bottle and the $\mathrm{pH}$ adjusted to 3.5. The sample was mixed for 30 minutes and centrifuged at $2500 \mathrm{x}$ g for 15 minutes. The sediment was retained and resuspended in $20 \mathrm{~mL}$ of sodium phosphate buffer ( $\mathrm{pH}$ 7.0). Following resuspension, the sample was transferred to a conical tube where the $\mathrm{pH}$ was adjusted to 7.0. Samples were incubated at $37 \pm 2{ }^{\circ} \mathrm{C}$ for $3-\mathrm{hr}$ with $1 \mathrm{~mL}$ of antibiotic/antimycotic $(10,000$ units $/ \mathrm{mL}$ of penicillin and $10,000 \mu \mathrm{g} / \mathrm{mL}$ of streptomycin, and $25 \mu \mathrm{g} / \mathrm{mL}$ of amphotericin B) and 0.1 $\mathrm{mL}$ of gentamicin $(50 \mathrm{mg} / \mathrm{mL})$ and frozen at $-80 \pm 2{ }^{\circ} \mathrm{C}$ for assay. The resuspended liquid or solid samples were homogenized and split into aliquots that were analyzed to enumerate viruses (adenovirus/MS2 or rotavirus/MS2).

\section{Lime Treatments}

Three biosolids matrices (raw, composted and previously limed) were spiked with viruses and lime treated at two temperatures $\left(22 \pm 2^{\circ} \mathrm{C}\right.$ and $\left.4 \pm 2^{\circ} \mathrm{C}\right)$. Control samples were processed in parallel, but not lime treated. Each condition was tested in triplicate. For each condition, samples were collected at five time points $(0$, $0.1,2,12$ and 24 hours) and viral concentrations determined. An initial trial was conducted in a $\mathrm{R} / \mathrm{O}$ water matrix at $22 \pm 2^{\circ} \mathrm{C}$. An $8 \%$ slurry composed of $\mathrm{Ca}(\mathrm{OH})_{2}$ in $\mathrm{R} / \mathrm{O}$ treated water was prepared for use during the challenge studies. Virus was inoculated independently into a beaker containing $50-\mathrm{mL}$ or $50-\mathrm{g}$ of sample matrix. For each time point, one beaker was designated as the Control and a second beaker designated as the Test beaker, with only the latter beaker receiving lime treatment. At each time point, the entire volume was removed from the designated test beaker (lime treated) and the designated control beaker (no addition of lime) for analysis. In addition, control samples were incorporated to evaluate the natural loss of virus infectivity over time as a result of temperature. These temperature controls consisted of aliquots of the virus stock incubated at room or reduced temperature, as appropriate, for the duration of the experiment. The control samples were analyzed concurrently with the experimental samples at the designated time points to evaluate viral loss over time due to storage temperature. Bacteriophage was included in all trials for each virus evaluated as an internal biological control and to evaluate the feasibility of using bacteriophage as a representative surrogate.

\section{Trials in Reverse Osmosis Water}

Adenovirus type 5 , rotavirus $\mathrm{Wa}$, and MS2 were initially evaluated in an RO water matrix that did not contain sludge or biosolids to provide a baseline for inactivation independent of the inhibitory components commonly found in sludge and biosolids matrices. RO water matrix trials were performed in triplicate at $22 \pm 5^{\circ} \mathrm{C}$. Fifty milliliter volumes of RO water in separate control and test beakers for time points $0.1,2,12$, and 24 hours were inoculated with adenovirus type 5 and MS2 to achieve a final concentration of $1.0 \times 10^{6} \mathrm{TCID}_{50} / \mathrm{mL}$ or $\mathrm{PFU} / \mathrm{mL}$ respectively. The same experimental design was employed in separate trials with rotavirus Wa and MS2 with inoculation of 50-mL volumes of RO water to achieve a final concentration of $1.0 \times 10^{4} \mathrm{PFU} / \mathrm{mL}$ for each virus. Samples were continually mixed with magnetic stir bars and $\mathrm{pH}$ and temperature readings were recorded for control and test beakers hourly. The $\mathrm{pH}$ of the test beakers for each time point was simultaneously adjusted to 12.0 using the 
$\mathrm{Ca}(\mathrm{OH})_{2}$ slurry. Approximately $0.4-0.5 \mathrm{~mL}$ of $\mathrm{Ca}(\mathrm{OH})_{2}$ slurry was required to elevate the $\mathrm{pH}$ to $=12.0$. The $\mathrm{pH}$ was maintained at $=12.0$ for 2 hours at which time, $0.1 \mathrm{~N}$ $\mathrm{HCl}$ was added until a $\mathrm{pH}$ value of 11.5 was achieved and maintained for 22 hours. The $\mathrm{pH}$ was reduced to simulate a worst-case scenario where the $\mathrm{pH}$ would have dropped to 11.5. Based on EPA guidelines, the $\mathrm{pH}$ of the material must not fall below 11.5 for a period of at least 22 hours. At time points $0.1,2,12$ and 24 hours, test beakers were neutralized with $0.1 \mathrm{~N} \mathrm{HCl}$ and the entire volume removed from designated control and test beakers for viral enumeration. An aliquot from the control and neutralized test sample was diluted in phosphate buffered saline and immediately assayed for the presence of male specific bacteriophage using the double agar overlay technique. The aliquots designated for adenovirus or rotavirus enumeration were centrifuged for 10 minutes at $1000 \times \mathrm{g}$ to remove precipitated lime, in an effort to minimize the toxic effects of the lime crystals during cell culture assay. Following centrifugation, the supernate was retained and assayed directly for the presence of adenovirus type 5 and rotavirus $\mathrm{Wa}$ by $\mathrm{TCID}_{50}$ and plaque assay respectively.

\section{Sludge Matrix Trials}

Sludge matrix trials were also performed at two temperatures $\left(22 \pm 5^{\circ} \mathrm{C}\right.$ and $\left.4 \pm 2^{\circ} \mathrm{C}\right)$ using the procedure described below. Fifty grams of various sludge matrices (composted ( $>50 \%$ total solids), raw $(<0.1 \%$ total solids) and previously limed ( $>5 \%$ total solids)), collected from participating utilities, was placed in separate control and test beakers for removal at time points $0.1,2,12$, and 24 hours. One hundred milliliters $(\mathrm{mL})$ of $\mathrm{R} / \mathrm{O}$ water was added to composted solids to facilitate mixing. Samples were inoculated with adenovirus Type 5 and MS2 to achieve a final concentration of approximately $1.0 \times 10^{5}$ $\mathrm{TCID}_{50} / \mathrm{mL}$ and approximately $1.0 \times 10^{7} \mathrm{PFU} / \mathrm{mL}$, respectively. The same experimental design was employed in separate trials using rotavirus Wa and MS2. Rotavirus Wa and MS2 were inoculated into various sludge samples to achieve a final concentration of approximately $1.0 \times 10^{4}$ $\mathrm{PFU} / \mathrm{mL}$ and $1.0 \times 10^{7} \mathrm{PFU} / \mathrm{mL}$, respectively. The $\mathrm{pH}$ of the test beakers was simultaneously adjusted to $=12.0$ using the $\mathrm{Ca}(\mathrm{OH})_{2}$ slurry (approximately $0.5 \mathrm{~mL}$ of slurry was typically required). The $\mathrm{pH}$ was maintained at $=12.0$ for 2 hours at which time, $0.1 \mathrm{~N} \mathrm{HCl}$ was added until a $\mathrm{pH}$ value of 11.5 was achieved and maintained for 22 hours. At time points $0.1,2,12$ and 24 hours, test beakers were neutralized with $0.1 \mathrm{~N} \mathrm{HCL}$ and aliquots were removed from designated control and test beakers for viral elution and enumeration as described above.

\section{Statistical Analysis}

Statistical analysis of lime stabilization trials was conducted using the SPSS ${ }^{\odot}$ statistical software package for Windows, Student Version 11.0.

\section{Results}

Adenovirus Type 5 and MS2 Lime Stabilization in Water and Sludge Matrices

Corroborating findings presented in an accompanying paper [20], in all trials conducted in water at room temperature, adenovirus was below detectable levels by $\mathrm{TCID}_{50}\left(<10^{0.5} \mathrm{TCID}_{50} / \mathrm{mL}\right)$ indicating inactivation following 0.1 hours of liming. The results of three trials conducted with adenovirus type 5 and MS2 inoculated into various sludge matrices at room temperature $\left(22 \pm 5^{\circ} \mathrm{C}\right)$ are presented in Fig 1.

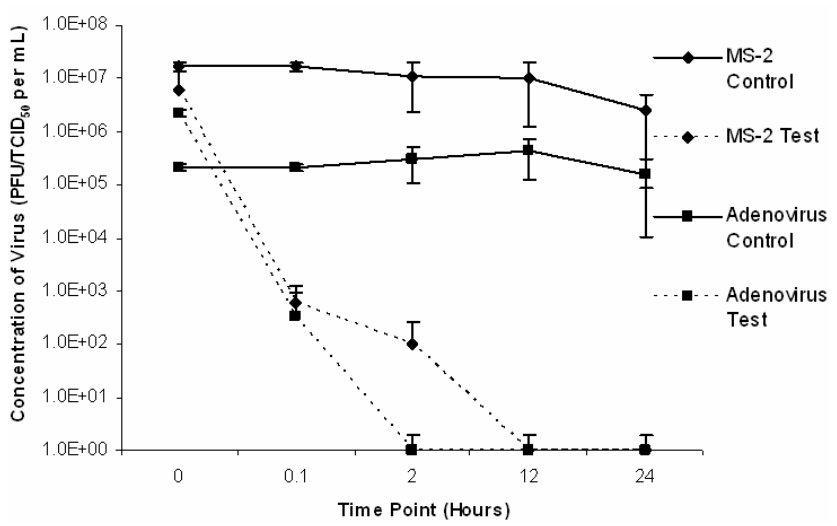

Figure 1: Average adenovirus type 5 and MS2 inactivation in sludge matrices (compost, raw and previously limed) lime stabilized at room temperature $\left(22 \pm 5^{\circ} \mathrm{C}\right)$.

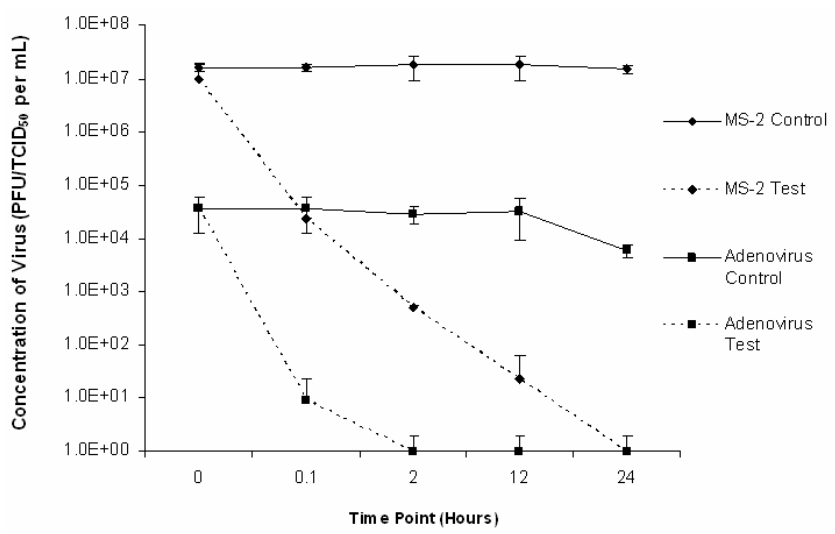

Figure 2: Average adenovirus type 5 and MS2 inactivation in sludge matrices (compost, raw and previously limed) lime stabilized at reduced temperature $\left(4 \pm 2^{\circ} \mathrm{C}\right)$.

The results of similar trials conducted at reduced temperature $\left(4 \pm 2^{\circ} \mathrm{C}\right)$ are presented in Fig 2 . In all sludge trials at room temperature and at $4{ }^{\circ} \mathrm{C}$ adenovirus was below detectable levels by $\operatorname{TCID}_{50}\left(<10^{0.5} \mathrm{TCID}_{50} / \mathrm{mL}\right)$ indicating inactivation following 24 hours of liming (time point 24). Inactivation rates varied with different matrices. In trials conducted at room temperature, adenovirus was inactivated at 2 hours, 0.1 hours and 0.1 hours for composted, previously limed and raw samples, respectively. In these same trials, MS2 was inactivated at 2 
hours, 12 hours, and 24 hours post-lime addition for composted, previously limed and raw samples respectively. In trials conducted at reduced temperature, adenovirus was determined to be below detectable levels at 2 hours, 0.1 hours, and 0.1 hours for composted, previously limed and raw samples, respectively. In these trials, MS2 was below detectable levels $(<1 \mathrm{PFU} / \mathrm{mL})$ at 24 hours, 12 hours and 12 hours for composted, previously limed and raw samples, respectively.

\section{Rotavirus Wa and MS2 Lime Stabilization Water at $22^{\circ} \mathrm{C}$}

The results of three trials conducted with rotavirus Wa and MS2 inoculated into a limed water matrix at room temperature $\left(22 \pm 5^{\circ} \mathrm{C}\right)$ are presented in Fig 3. In all trials, rotavirus was below detectable levels $(<1 \mathrm{PFU} / \mathrm{mL})$ by plaque assay indicating inactivation following 0.1 hours of liming. In all trials, MS2 was below detectable levels $(<1$ PFU/mL) following 2 hours of liming. Similarly, in all control RO water trials both rotavirus and MS2 were below detectable levels following 0.1 and 2 hours of liming, respectively, exhibiting at least a four log reduction for both viruses.

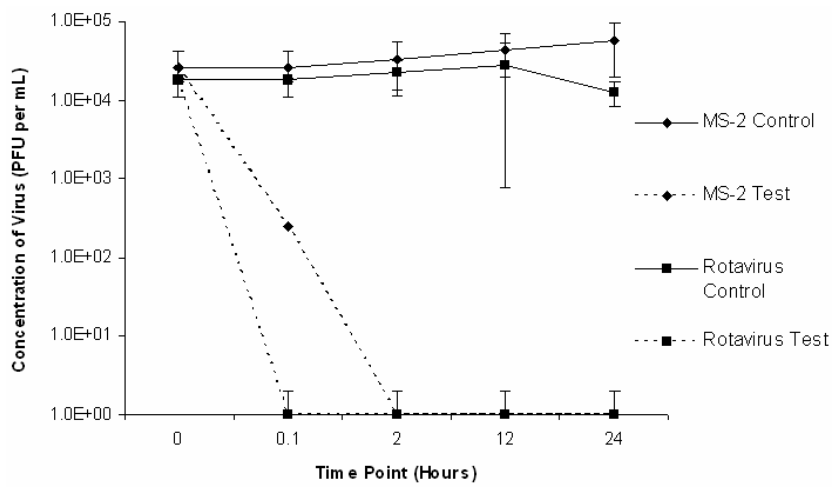

Figure 3: Rotavirus Wa and MS2 persistence in a test lime and control RO water matrix at room temperature (22 \pm $\left.5^{\circ} \mathrm{C}\right)$.

Rotavirus Wa and MS2 Lime Stabilization in Sludge Matrices at $22^{\circ} \mathrm{C}$ and $4^{\circ} \mathrm{C}$

The results of three trials conducted with rotavirus Wa and MS2 inoculated into a various sludge matrices at room temperature $\left(22 \pm 5^{\circ} \mathrm{C}\right)$ are presented in Fig. 4 . The results of similar trials conducted at reduced temperature $(4 \pm$ $2^{\circ} \mathrm{C}$ ) are presented in Fig. 5. In all sludge trials conducted at room temperature and reduced temperature, rotavirus was below detectable levels by plaque assay $(<1 \mathrm{PFU} / \mathrm{mL})$ indicating inactivation following 0.1 hours of liming (time point 0.1 hours). Inactivation rates varied with different matrices. In trials conducted at room temperature, rotavirus was inactivated at 0.1 hours following the addition of lime for composted, previously limed and raw samples respectively. In these same trials, MS2 was below detectable levels $(<1 \mathrm{PFU} / \mathrm{mL})$ at 2 hours, 2 hours, and 12 hours post-lime addition for composted, previously limed and raw samples, respectively. In trials conducted at reduced temperature, rotavirus was below detectable levels $(<1 \mathrm{PFU} / \mathrm{mL})$ at 0.1 hours following the addition of lime for composted, previously limed and raw samples respectively. In these trials, MS2 was below detectable levels $(<1 \mathrm{PFU} / \mathrm{mL})$ at 12 hours, 12 hours and 24 hours for composted, previously limed and raw samples, respectively.

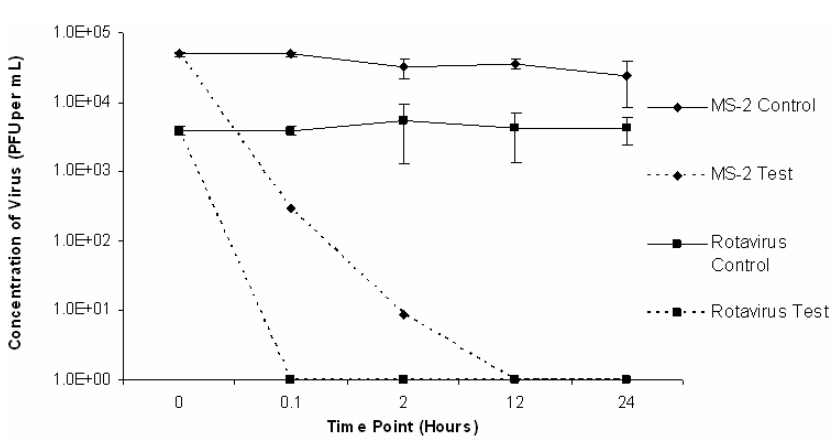

Figure 4: Average rotavirus Wa and MS2 inactivation in sludge matrices (compost, raw and previously limed) lime stabilized at room temperature $\left(22 \pm 5^{\circ} \mathrm{C}\right)$.

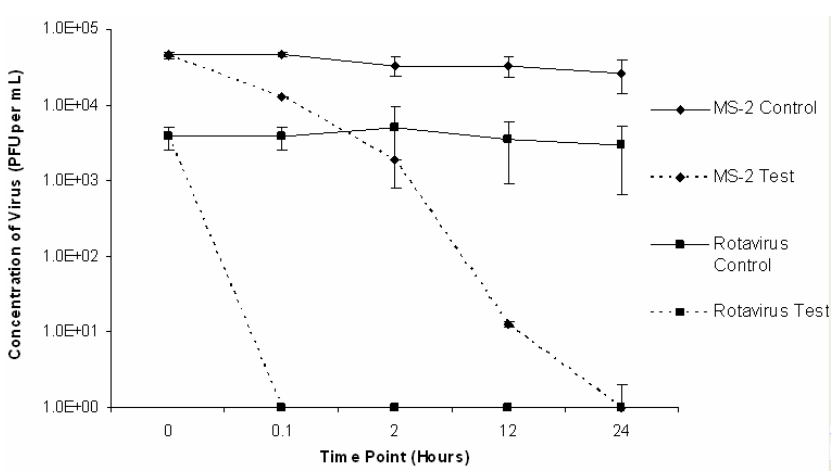

Figure 5: Average rotavirus Wa and MS2 inactivation in sludge matrices (compost, raw and previously limed) lime stabilized at reduced temperature $\left(4 \pm 2^{\circ} \mathrm{C}\right)$.

\section{Statistical Analysis}

Analysis of variance in treatment effectiveness for inactivation of adenovirus type 5, rotavirus Wa and MS2 in a $\mathrm{R} / \mathrm{O}$ water matrix indicated, with $95 \%$ confidence, no significant difference between the effect of lime treatment on adenovirus and MS2 or rotavirus Wa and MS2 ( $\mathrm{p}$ value $=0.119$ and 0.431 , respectively). The effect of treatment on adenovirus type 5, rotavirus and MS2 was significant ( $\mathrm{p}$ $=0.000$ ). Statistical analysis of three trials of adenovirus type 5 and MS2 and rotavirus Wa and MS2 lime stabilization, evaluated in various sludge matrices (compost, limed, raw) at room temperature and reduced temperature, revealed a statistically significant effect of treatment on all viruses ( $\mathrm{p}$ value $=0.000$ ). In addition, no significant difference was observed between the effect of liming on adenovirus type 5 and MS2 at either temperature $(\mathrm{p}=0.315$ at room temperature, $\mathrm{p}=0.072$ at reduced temperature). No significant difference was observed 
between the effect of liming on rotavirus Wa and MS2 at either temperature range $(\mathrm{p}=0.315$ at room temperature, $\mathrm{p}$ value $=0.184$ at reduced temperature) .

The percent inactivation for virus and bacteriophage was calculated for each time point in each trial. The percent recovery was used in statistical analysis to draw comparisons between organisms due to a difference in starting concentrations. For trials conducted at room temperature, there was no statistically significant effect of time on the inactivation of virus or bacteriophage by lime stabilization $(p>0.05)$. Time points of less than 0.1 hours treatment were impractical due to the experimental design and were not evaluated. In contrast, the efficacy of lime treatment was observed to be time dependent in reduced temperature trials. At reduced temperature, the effect of time did not differ significantly between organisms ( $p$ value $=0.352$ ). Therefore, these data indicate no statistically significant difference between the effects of liming over time on adenovirus or MS2 during lime stabilization. The variation between trials was not evaluated statistically because no two sludge samples or aliquots of a single sludge matrix are the same. Therefore, in an effort to obtain information about the effect of lime stabilization, it was most practical to evaluate liming in several different matrices rather than different samples from the same matrix that are not consistent.

Analysis of variance in percent reduction values generated for adenovirus type 5, rotavirus Wa, and MS2 was conducted using the SPSS statistical software package. Comparisons were made between trials evaluated at $22 \pm$ $5^{\circ} \mathrm{C}$ and $4 \pm 2^{\circ} \mathrm{C}$ in an effort to determine if liming conducted at lower temperatures affected the inactivation of virus and bacteriophage. Bacteriophage data from all trials conducted at room temperature and reduced temperature were compiled and analyzed. The results of such analysis revealed a significant effect of treatment regardless of temperature $(\mathrm{p}$ value $=0.000)$, and no significant difference in treatment effectiveness for inactivation of MS2 at either temperature ( $\mathrm{p}$ value = 0.201). The same result was true for adenovirus type 5; the effect of treatment with lime was significant at both temperatures $(\mathrm{p}$ value $=0.000)$ and there was no significant difference in treatment effectiveness at different temperatures $(\mathrm{p}$ value $=0.856$ ). Rotavirus was not detected in any of the test samples analyzed in any of the matrices at either temperature evaluated; there was no difference between samples or temperatures.

\section{Discussion}

Lime stabilization is a method employed by many sludge generators to inactivate pathogens, immobilize heavy metals, modify acidic soils, and reduce vector attraction. The use of lime as a treatment method is inexpensive with regard to cost of implementation and operation, and generates a product that is beneficial and acceptable for agricultural use. The evaluation of reliable and cost-effective treatment processes to demonstrate sufficient inactivation of pathogens provides valuable information for implementation of treatment technologies. Very little data exist describing pathogen persistence under lime stabilization conditions. The goal of this study was to evaluate the inactivation of virus and bacteriophage under conditions simulating the lime treatment process in sludge and biosolids matrices. Studies were performed at room temperature $\left(22 \pm 5^{\circ} \mathrm{C}\right)$ and reduced temperature $\left(4 \pm 2^{\circ} \mathrm{C}\right)$.

Enteric viruses are of particular importance with regard to land application of biosolids due to the potential for runoff resulting in surface water contamination and the potential for viral movement through the soil column into underground aquifers. Such movement is enhanced during a rain event where the cation concentration and overall binding of viruses to soil particulates is reduced and will vary with soil composition. In addition to evaluating adenovirus and rotavirus, male specific bacteriophage was also assessed. The rationale for this was two-fold. Male specific bacteriophages were incorporated as a biological internal control for all experiments and as a means of comparing trials for individual organisms and trials between classes of organisms.

Viruses were initially evaluated in an $\mathrm{RO}$ water matrix to assess inactivation as a result of lime addition independent of the many inhibitory substances that may be present in sludge and biosolids matrices, and to obtain a baseline inactivation for viral pathogens in a water matrix ${ }^{20}$. The water matrix represents a best-case scenario for inactivation of pathogens since it has been documented that organic material and particulate matter enhance the survival of microorganisms potentially contained within biosolids material.

The results of the water matrix trials indicate that lime stabilization effectively inactivated adenovirus type 5, rotavirus $\mathrm{Wa}$ and male-specific bacteriophage MS2 in a water matrix at room temperature $\left(22 \pm 5^{\circ} \mathrm{C}\right)$ essentially immediately upon addition of lime. In addition, analysis of the $\mathrm{R} / \mathrm{O}$ water results revealed no significant difference between the effect of lime treatment for any of the viruses evaluated and more specifically, that male specific bacteriophages are inactivated similarly to both adenovirus type 5 and rotavirus Wa. Subsequent experimentation to evaluate inactivation in sludge (raw) and biosolids (treated) matrices demonstrated that lime stabilization was effective at reducing adenovirus type 5 , rotavirus $\mathrm{Wa}$, and malespecific bacteriophage to below detectable levels at room temperature $\left(22 \pm 5^{\circ} \mathrm{C}\right)$ and reduced temperature $\left(4 \pm 2^{\circ} \mathrm{C}\right)$. Under these conditions, the data also demonstrate that male specific bacteriophages were inactivated similarly to both adenovirus type 5 and rotavirus $\mathrm{Wa}$ and therefore represent a potential indicator or surrogate to evaluate viral inactivation or treatment efficiency.

The current methodology established in the EPA Part 503 rule for recovering enteric viruses from biosolids is extremely inefficient; this is due in part to the particle association that takes place between charged viruses and soil particles and the difficulty in separating the viruses from the solid component for assay. As a result, routine monitoring of enteric virus from biosolids samples generally fails to recover enteric virus. Such results 
suggest that the biosolids are in compliance with regulations and therefore suitable for land application. Our data suggest that bacteriophage, which is easily recovered from sludge and biosolids matrices, may provide a screening tool and a process control that can be used in conjunction with monitoring of enteric virus.

In order to achieve inactivation rates demonstrated in this investigation it was necessary that the matrix be adequately mixed and the lime added to achieve a homogeneous distribution in the sample. If the sludge were not adequately mixed, microenvironments may be created which would not be exposed to the high $\mathrm{pH}$ levels necessary for viral inactivation. Therefore, effective liming is contingent upon the lime coming in contact with the sludge particulates in a homogenous mixture, thereby ensuring that microenvironments do not form.

While not statistically significant, these data indicate that adenovirus type 5 and rotavirus Wa were inactivated more rapidly than MS2. In addition, bacteriophage are present in high concentrations in raw sludge and are easily recoverable from most matrices using rapid, reliable and cost-effective methods. While additional research is needed using different treatments and human enteric viruses, this study suggests the potential use of bacteriophage as a conservative indicator of the fate of human viruses in treatment processes.

\section{References}

1. Farrell, J. B.; Smith, J. E., Jr.; Hathaway, S. W.; Dean, R. B.: Lime stabilization of primary sludges. $J$ Water Pollut Control Fed, 1974, 46, (1), 113-22.

2. Grabow, W. O.; Middendorff, I. G.; Basson, N. C.: Role of lime treatment in the removal of bacteria, enteric viruses, and coliphages in a wastewater reclamation plant. Appl Environ Microbiol., 1978, 35, (4), 663-9.

3. Mignotte-Cadiergues, B.; Maul, A.; Huyard, A.; Capizzi, S.; Schwartzbrod, L.: The effect of liming on the microbiological quality of urban sludge. Water Sci Technol., 2001, 43, (12), 195-200.

4. Mignotte-Cadiergues, B.; Gantzer, C.; Schwartzbrod, L.: Evaluation of bacteriophages during the treatment of sludge. Water Sci Technol., 2002, 46, (10), 189-94.

5. Wong, J. W. C.; Fang, M.: Effects of lime addition on sewage sludge composting process. Water Research, 2000, 34, (15), 3691-3698.

6. Wong, J. W.; Fang, M.; Jiang, R.: Persistency of bacterial indicators in biosolids stabilization with coal fly ash and lime. Water Environ Res., 2001, 73, (5), 607-11.

7. Deng, M. Y.; Cliver, D. O.: Inactivation of poliovirus type 1 in mixed human and swine wastes and by bacteria from swine manure. Appl. Environ Microbiol., 1992, 58, (6), 2016-21.
8. Derbyshire, J. B.; Brown, E. G., The inactivation of viruses in cattle and pig slurry by aeration or treatment with calcium hydroxide. J. Hyg (Lond), 1979, 82, (2), 293-9.

9. Sattar, S. A.; Ramia, S.; Westwood, J. C.: Calcium hydroxide (lime) and the elimination of human pathogenic viruses from sewage: studies with experimentally-contaminated (poliovirus type 1, Sabin) and pilot plant samples. Can J. Public Health 1976, 67, (3), 221-5.

10. Wyatt, R. G.; James, W. D.; Bohl, E. H.; Theil, K. W.; Saif, L. J.; Kalica, A. R.; Greenberg, H. B.; Kapikian, A. Z.; Chanock, R. M.: Human rotavirus type 2: cultivation in vitro. Science, 1980, 207, (4427), 189-91.

11. Chapron, C. D.; Ballester, N. A.; Fontaine, J. H.; Frades, C. N.; Margolin, A. B.: Detection of astroviruses, enteroviruses, and adenovirus types 40 and 41 in surface waters collected and evaluated by the information collection rule and an integrated cell culture-nested PCR procedure. Appl Environ Microbiol., 2000, 66, (6), 2520-5.

12. Estes, M. K.; Kang, G.; Zeng, C. Q.; Crawford, S. E.; Ciarlet, M.: Pathogenesis of rotavirus gastroenteritis. Novartis Found Symp 2001, 238, 82-96; discussion 96-100.

13. Gerba, C. P.; Rose, J. B.; Haas, C. N.: Sensitive populations: who is at the greatest risk? Int J Food Microbiol 1996, 30, (1-2), 113-23.

14. Papapetropoulou, M.; Vantarakis, A. C.: Detection of adenovirus outbreak at a municipal swimming pool by nested PCR amplification. J. Infect, 1998, 36(1), 101-3.

15. Enriquez, C. E.; Hurst, C. J.; Gerba, C. P.: Survival of the Enteric Adenovirus-40 and Adenovirus-41 in Tap, Sea, and Waste-Water. Water Research, 1995, 29, (11), 2548-2553.

16. Adams, M. H.: Bacteriophages. Interscience: New York, NY, 1959.

17. Smith, E. M.; Estes, M. K.; Graham, D. Y.; Gerba, C. P., A plaque assay for the simian rotavirus SAII. $J$ Gen Virol., 1979, 43, (3), 513-9.

18. Reed, L. J.; Muench H.: A simple method of estimating fifty per cent endpoints. American Journal of Hygiene, 1938, 27, (3), 493-497.

19. EPA Environmental Regulations and Technology: Control of Pathogens and Vector Attraction in Sewage Sludge; Washington, D.C.: 1999, pp EPA/625/R-92/013.

20. Bean, C. L.; Hansen J. J.; Margolin A. B.; Balkin, H.; Batzer, G.; Widmer, G.: Class B alkaline stabilization to achieve pathogen inactivation (submitted). 